\title{
Removal of phosphorus by a high rate membrane adsorption hybrid system
}

\author{
M.A.H. Johir, Tien Thanh Nguyen, K. Mahatheva, M. Pradhan, Huu Hao Ngo, Wenshan Guo, \\ Saravanamuth Vigneswaran*
}

\author{
School of Civil and Environmental Engineering, University of Technology Sydney, Broadway, NSW 2007, Australia \\ *Corresponding author. Tel.: +61 29514 2641; fax: +61 29514 2633. E-mail address: \\ Saravanamuth.Vigneswaran@uts.edu.au (S. Vigneswaran)
}

\begin{abstract}
Membrane adsorption hybrid system (MAHS) was evaluated for the removal of phosphate from a high rate membrane bioreactor (HR-MBR) effluent. The HR-MBR was operated at permeate flux of $30 \mathrm{~L} / \mathrm{m}^{2} \mathrm{~h}$. The results indicated that the HR-MBR could eliminate $93.1 \pm 1.5 \%$ of DOC while removing less than 53\% phosphate (PO4-P). Due to low phosphate removal by HR-MBR, a post-treatment of strong base anion exchange resin (Dowex $21 \mathrm{~K}-\mathrm{XLT}$ ), and zirconium (IV) hydroxide were used as adsorbent in MAHS for further removal of phosphate from HR-MBR effluent. It was found that the MAHS enabled to eliminate more than 85\% of PO4-P from HR-MBR effluent. Hence, HR-MBR followed by MAHS lead to simultaneous removal of organics and phosphate in a reliable manner. The experiments were conducted only for a short period to investigate the efficiency of these resins/adsorbents on the removal of phosphorus and high rate MBR for organic removal.
\end{abstract}

Keywords: High rate membrane bioreactor; Membrane adsorption hybrid system; Organic removal; Phosphate removal

\section{Introduction}

Membrane bioreactor (MBR) has been considered as a state-of- the-art technology in wastewater treatment during the last few decades. Admittedly, this technology has several advantages over the conventional treatment systems, such as high treated water quality, less space requirement, and less sludge production. High permeate flux plays primary role in reducing operating cost per cubic treated water, and shortens hydraulic retention time (HRT). However, operating MBR at high filtration flux also means reducing treatment efficiency and increasing membrane fouling.

Filtration flux plays an important role on organics and nutrients removal efficiency. Johir et al. (2012) studied the effect of imposed flux on fouling behaviour and organic removal efficiency in high rate membrane bioreactor. This study showed that the highest DOC removal of around 95\% was achieved when the MBR was operated below a flux of $20 \mathrm{~L} / \mathrm{m}^{2} \mathrm{~h}$. This removal efficiency reduced to $58-66 \%$ when the operating flux was increased to $40 \mathrm{~L} / \mathrm{m}^{2} \mathrm{~h}$. Nutrient removal efficiency also presented the similar fashion as $\mathrm{NH}_{4}-\mathrm{N}$ removal was $50 \%$ and 30-35\% when operating at 20 and $40 \mathrm{~L} / \mathrm{m}^{2} \quad \mathrm{~h}$, respectively.

Biological nutrient removal is more difficult to achieve with the MBR, and phosphate $(\mathrm{P})$ is the most difficult one to remove (Sun et al., 2013). Indeed, the removal of phosphate by MBR can be improved through the incorporation of polyphosphate accumula- tive organisms (PAO) or denitrifying poly-phosphate accumulating organisms (DPAOs) (Monclús et al., 2010). They have reported an average $\mathrm{P}$ removal of $88 \%$. Further, Sun et al. (2013) tested an inno- vative membrane bioreactor (MBR) system (membrane filtration system coupled with a postde-nitrification process) for effective organic degradation and nutrient ( $\mathrm{N}$ and $\mathrm{P}$ ) removal and the total removal of $\mathrm{P}$ found to be around $87 \%$. However, this is a complex process and the efficiency reduced when the phosphate concentra- tion was high (Long et al., 2011). On the other hand, ion exchange/ adsorption processes effectively remove nitrate, phosphate and 
ammonia from water and wastewater to near zero level in a reliable manner (Samatya et al., 2006; Johir et al., 2011a). Ion exchange resins and adsorbents such as purolite A500P, purolite A520E, amberlite IRA910Cl (a strong basic macroreticular anion exchange resin), amberjet $1200 \mathrm{Na}$ (a strong acid cation exchanger), aluminium oxide, iron oxide, zirconium oxide, hydrotalcite, (Chen et al., 2002; Johir et al., 2011a) were successfully tested for superior P removal. Nur et al. (2014) reported a maximum adsorption capacity of $48 \mathrm{mg} \mathrm{P} / \mathrm{g}$ by iron oxide impregnated strong base anion exchange resin. Further, Liu et al. (2008) reported a maximum P adsorption capacity of $29.71 \mathrm{mg} \mathrm{P} / \mathrm{g}$ by mesoporous $\mathrm{ZrO}_{2}$.

The use of ion exchange resin/adsorbent offers a number of advantages including the ability to handle shock loadings and the ability to operate over a wider range of temperatures. Furthermore, the ion exchange resin/adsorbent can be regenerated and used for several cycles before their adsorption capacity significantly decreased (Nur et al., 2014). Another major advantage of ionexchange process is that adsorbed nutrients can be recovered during regeneration and can be used as fertigation. Johir et al. (2011a) and Samatya et al. (2006) reported a recovery of 90-95\% of nitrate and phosphate by using $\mathrm{NaCl}$ as a regenerating solution. Other mild alkaline solution such as $\mathrm{NaOH}, \mathrm{Na}_{2} \mathrm{SO}_{4}$ can also be used as regenerating solution. Thus, it is reliable to use HR-MBR with the intention of removing mainly biological oxygen demand (BOD) and ion exchange process for the removal and recovery of phosphate. This is considered advantageous for a smaller MBR reactor volume, and a correspondingly lower capital cost, and a lower oxygen demand, and also allows a maximum recovery of nutrients in the sludge, and a greater reuse potential of carbon from grey water.

Even though many researches were conducted on the removal of phosphorus using different types of adsorbent but they were mainly confined to batch and column adsorption studies only. Practically, no study was conducted with MAHS for the removal of phosphate from HR-MBR effluent. This study used a dual membrane system consisting of a high rate MBR mainly to remove organic matters and MAHS to remove nutrients to near zero level with short term experiments. The use of MBR as an upstream process to the ion exchange process eliminates the flow resistance in the ion exchange column as all particulate matter (causing turbidity) would have been removed by the MBR. The incorporation of MAHS will ensure reliable removal of nutrients and also pave a way for recovery of nutrients. Thus, this study will be very useful in the design of continuous membrane absorption systems for the removal of phosphorus and organic simultaneously.

\section{Methods}

\subsection{Synthetic wastewater}

The experiments were conducted using a synthetic wastewater based on previous study (Nguyen et al., 2012). This represents high strength domestic wastewater. The synthetic wastewater consists of DOC of 120-130 mg/L, COD of 330-360 mg/L, ammonium nitrogen $\left(\mathrm{NH}_{4}-\mathrm{N}\right)$ of $12-15 \mathrm{mg} / \mathrm{L}$ and orthophosphate $\left(\mathrm{PO}_{4}-\mathrm{P}\right)$ of 3.3-3.5 mg/L as source of organic and nutrients. The ratio of COD:N:P was 100:5:1).

The synthetic feed contained mostly biodegradable dissolved COD which is easily biodegradable. On the other hand, the real feed contains wide range of physico-chemical and microbiological pollutants. The suspended solid concentration in real feed varies significantly and also contains both particulate and nonbiodegradable COD. However, the synthetic feed has advantages over real feed in the experimental investigation as its physicochemical and microbiological characteristics can be kept constant. Further, it is also easy to vary the influent concentration of the substrate in the synthetic feed by changing the quantities of the ingredients. The use of real wastewater will also lead to similar trend of results.

\subsection{HR-MBR \\ description}

In this study, a HR-MBR was operated at a flux of $30 \mathrm{~L} / \mathrm{m}^{2} \mathrm{~h}$ which corresponded to a hydraulic retention time (HRT) of $2.5 \mathrm{~h}$. From literature, it is found that different full-scale MBRs used an operating flux ranges between $21-33 \mathrm{~L} / \mathrm{m}^{2} \mathrm{~h}$ (EUROMBRA, 2005). As such, in this study, an operating flux of $30 \mathrm{LMH}$ was used. Past study also suggested that HR-MBR can be suitable for organic removal (Johir et al., 2011b). A flat sheet membrane with surface area of $0.2 \mathrm{~m}^{2}$ and an average pore size of $0.14 \mathrm{~lm}$ and was placed in the reactor. The volume of reactor used in this study was $15 \mathrm{~L}$. The membrane module had 8 vertical sheets and the gap between adjacent vertical membrane sheets was $12 \mathrm{~mm}$. A predetermined

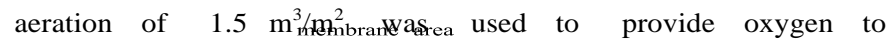
microorganism and to provide shearing stress on the membrane surface. The HR-MBR was stopped for 8 mins (relaxation mode), for every $120 \mathrm{~min}$ of operation. No backwashing was applied during experiment. The trans- membrane pressure (TMP) was monitored continuously using a pressure transducers and the reading were recorded in the data logger.

\subsection{Membrane adsorption hybrid system (MAHS) for phosphorus removal from HR-MBR effluent}

In this study, 2 different types of ion-exchange resins/adsorbents namely Dowex $21 \mathrm{~K}$ XLT (strong base anion exchange resin), and zirconium (IV) hydroxide were used in the post treatment of membrane adsorption hybrid system (MAHS) for the removal of phosphate from HR-MBR effluent. The properties of these resins/ adsorbents are presented in Table 1.

The effluent from HR-MBR was used as feed to MAHS. Hollow fibre micro-filter membrane module (MANN + HUMMEL, Singapore) with an area of $0.1 \mathrm{~m}^{2}$ made of hydrophilic modified poly

Table 1

The properties of the adsorbents/ion exchange resins used in this study.

\begin{tabular}{lll}
\hline Parameters & DOWEX'21K XLT & Zirconium (IV) hydroxide \\
\hline Matrix structure & Type I strong base anion, styrene-DVB, gel & $\mathrm{H}_{4} \mathrm{O}_{4} \mathrm{Zr}$ \\
Functional groups & Quaternary amine & - \\
Ionic form (as shipped) & $\mathrm{Cl}^{-}$ & - \\
Particle size range (microns) & $525-625$ & $<35$ \\
Uniformity coefficient, max. & $1.1 \%$ & - \\
Particle density $\left(\mathrm{kg} / \mathrm{m}^{3}\right)$ & 1080 & $1100-1300$ \\
Total exchange capacity & $1.4 \mathrm{eq} / \mathrm{l} \mathrm{min}$ & - \\
Total swelling $(\mathrm{Cl})$ OH), approx. & $18-20 \%$ & - \\
Maximum operating temperatures & 100 oC $\left(\mathrm{Cl}^{-}\right.$form) & - \\
pH range & $0-14$ & - \\
Water content & $50-60 \%$ & \\
\hline
\end{tabular}


acrylic nitrile (PAN) (inner and outer diameter of fibre was 1.1 and $2.1 \mathrm{~mm}$ respectively) was used in MHAS. The average pore size of the membrane was $0.1 \mathrm{~lm}$. The reactor tank of $4 \mathrm{~L}$ capacity was filled to $3 \mathrm{~L}$ and the membrane module was placed in the centre of tank: just above the aerator plate. The filtration system was operated at a constant flux of $5 \mathrm{~L} / \mathrm{m}^{2} \mathrm{~h}$ using a peristaltic pump to maintain a constant permeates flux. In this study, the operation of MAHS was not optimised. The aim of this study was mainly to find out the effect adsorbent doses on the removal of phosphate from HR-MBR effluent without changing any hydrodynamic parameter such as flux. The operational flux can be increased by using a reactor of larger volume. For example, instead of using a reactor of $4 \mathrm{~L}$ capacity, the operational flux could be increased to $30 \mathrm{~L} / \mathrm{m}^{2} \mathrm{~h}$ with a $20 \mathrm{~L}$ capacity of reactor (without changing the contact time of ion exchanger/adsorbent). Transmembrane pressure (TMP) was measured by a pressure transducer installed between the suction pump and the membrane. Air bubbles were continuously injected at a fixed rate $\left(1.8 \mathrm{~m}^{3} / \mathrm{m}_{\text {membrane area }}^{2} \mathrm{~h}\right)$ from the bottom of the tank to keep the resins/adsorbent in suspension.

\subsection{Analysis}

DOC of the influent and effluent was measured using the Analytikjena Multi N/C 3100. $\mathrm{PO}_{4}-\mathrm{P}$ was measured by photometric method using Spectroquant ${ }^{\circledR}$ Cell Test (NOVA 60, Merck). Mixed liquor suspended solid (MLSS) and mixed liquor volatile suspended solids (MLVSS) was measured according to standard methods (APHA, 1998).

\section{Results and discussion}

\subsection{Performance of HR-MBR}

\subsubsection{Biomass concentration}

At the beginning of the experiment the concentration of MLSS and MLVSS of the activated sludge were $5.4 \pm 0.3 \mathrm{~g} / \mathrm{L}$ and $4.3 \pm 0.6 \mathrm{~g} / \mathrm{L}$ respectively. The biomass concentrations in the MBR in terms of MLSS and MLVSS were increased to $23.0 \pm 1.2$ and $19.5 \pm 0.7 \mathrm{~g} / \mathrm{L}$ respectively during the operation period. The sludge was not withdrawn from the reactor. However, long term operation requires withdrawal/purge of sludge on a regular basis which will help to reduce membrane fouling and will also eliminate the accumulation of toxic matter in MBR. The rate of increase of MLSS and MLVSS was $0.60 \pm 0.05$ and $0.5 \pm 0.05 \mathrm{~g} / \mathrm{d}$. This increasing rate was higher than that observed from previous study. Nguyen et al. (2012) reported increment rate of the MLSS concentration of $0.11-$ $0.18 \mathrm{~g} / \mathrm{d}$ when operating submerged MBR at different sludge concentrations with sponge as supported medium. Nguyen et al. (2012) used a lower filtration flux of $10 \mathrm{~L} / \mathrm{m}^{2} \mathrm{~h}$ whereas the present study used a filtration flux of $30 \mathrm{~L} / \mathrm{m}^{2} \mathrm{~h}$. Thus, the change of hydrodynamic condition may alter the result to some extent.

\subsubsection{Organic and phosphorus removal}

The removal efficiency of DOC by HR-MBR was relatively good at $93.1 \pm 1.5 \%$. This result is in agreement with previous studies. Nguyen et al. (2012) reported DOC removal efficiency of more than $90 \%$ by MBR with and without addition of the addition of sponge.

$\mathrm{PO}_{4}-\mathrm{P}$ removal efficiency of the HR-MBR system was $53.2 \pm 6.6 \%$. Phosphorus removal mechanisms in wastewater could be either by precipitation and/or adsorption, or by cell metabolism and growth (Radjenović et al., 2008). The amount of phosphorus removed was calculated based on influent and effluent concentration of phosphorus on daily basis. The average removal of phosphorus was around 18.8-57.2 $\mathrm{mg} \mathrm{P} / \mathrm{g}$. MLSS.d.

\subsection{MAHS for the removal of phosphorus from HR-MBR effluent}

As the phosphate removal was not sufficient by HR-MBR, a post treatment of MAHS was used. Two types of adsorbents namely Dowex $21 \mathrm{~K} \mathrm{XLT}$, and zirconium (IV) hydroxide were used in MAHS. Initially, the adsorption capacity of these two ion exchange resins/ adsorbent was assessed through batch adsorption equilibrium experiments at different concentrations of the resins/adsorbent of $0.1-10 \mathrm{~g} / \mathrm{L}$. The equilibrium data were then fitted (figures are not showing here) using Langmuir adsorption isotherm model to calculate the maximum adsorption capacity $\left(\mathrm{Q}_{\max }\right)$ of the resins/ adsorbent using following equation.

$$
\frac{C_{e}}{q_{e}}=\frac{1}{Q_{\max } K_{L}}+\frac{C_{e}}{Q_{\max }}
$$

where, $C_{e}=$ the equilibrium concentration of the adsorbate $(\mathrm{mg} / \mathrm{L})$, $\mathrm{q}_{\mathrm{e}}=$ the amount of adsorbate adsorbed per unit mass of adsorbent $(\mathrm{mg} / \mathrm{g}), \mathrm{Q}_{\max }=$ the maximum amount of the adsorbate per unit weight of the adsorbent (mg/g); $\mathrm{K}_{\mathrm{L}}=$ Langmuir constant $(\mathrm{L} / \mathrm{mg})$.

From the experimental investigation, the maximum adsorption capacity of P by Dowex $21 \mathrm{~K}$ XLT and zirconium (IV) hydroxide were found to be $11.7 \mathrm{mg}-\mathrm{P} / \mathrm{g} \quad\left(\mathrm{K}_{\mathrm{L}}=0.30 \mathrm{~L} / \mathrm{mg} ; \mathrm{R}^{2}=0.70\right)$ and $24.70 \mathrm{mg}-\mathrm{P} / \mathrm{g}\left(\mathrm{K}_{\mathrm{L}}=0.30 \mathrm{~L} / \mathrm{mg} ; \mathrm{R}^{2}=0.89\right)$ respectively. Following batch equilibrium experiment, membrane adsorption hybrid system experiments were conducted with different concentration of ion exchange resins/ adsorbents of 1,3 and $5 \mathrm{~g} / \mathrm{L}$ of the volume of the reactor (i.e. 3,9 and $15 \mathrm{~g}$ of the adsorbent was added at the beginning of the each experiment, no further adsorbent was added afterwards during the experiment) to study the removal of phosphate. In the long term operation of MAHS system, a predetermined amount of ion exchanger/adsorbent was removed and replaced with new ion exchange material/adsorbent. The amount to be removed is calculated based on the ion exchange/ adsorptive capacity of ion exchange/adsorbent. The previous studies have adopted this method (Shanmuganathan et al., 2015). The experimental results showed that the removal efficiency of $\mathrm{PO}_{4}-\mathrm{P}$ increased with the increase in resin or adsorbent dose as expected (Fig. 1). Furthermore, it can be seen in Fig. 1, zirconium (IV) hydroxide showed relatively higher removal of $\mathrm{P}$ than Dowex throughout the experimental period of $6 \mathrm{~h}$. This is due to higher adsorption capacity of $\mathrm{P}$ by zirconium (IV) hydroxide $(24.70 \mathrm{mg}-$

$\left.\mathrm{P} / \mathrm{g} ; \quad \mathrm{K}_{\mathrm{L}}=0.30 \mathrm{~L} / \mathrm{mg} ; \quad \mathrm{R}=0.89\right) \quad$ than Dowex $(11.7 \mathrm{mg}-\mathrm{P} / \mathrm{g}$; $\mathrm{K}_{\mathrm{L}}=0.30 \mathrm{~L} / \mathrm{mg} ; \mathrm{R}=0.70$ ). Another important reason could be due to the competitive adsorption between nitrate, phosphate and sulphate. The effluent collected from HR-MBR was rich in nitrate (around $10 \mathrm{mg} / \mathrm{L}$ ) as well as sulphate (around $30 \mathrm{mg} / \mathrm{L}$ ). Thus nitrate and sulphate could also be adsorbed by Dowex (in competition with P) which was confirmed through our initial experimental investigation. It was found that Dowex has relatively high adsorption capacity of nitrate $\left(1.24 \mathrm{mg}-\mathrm{N} / \mathrm{g} ; \mathrm{K}_{\mathrm{L}}=3.41 \mathrm{~L} / \mathrm{mg}\right.$; $\left.\mathrm{R}^{2}=0.87\right)$ and sulphate (17.0 mg-S/g; $\left.\mathrm{K}_{\mathrm{L}}=1.35 \mathrm{~L} / \mathrm{mg} ; \mathrm{R}^{2}=0.98\right)$ than zirconium (IV) hydroxide. Zirconium (IV) hydroxide on the other hand did not adsorb any nitrate and had a very low adsorption capacity of sulphate of less than $5 \mathrm{mg}-\mathrm{S} / \mathrm{g}\left(\mathrm{K}_{\mathrm{L}}=-0.12 \mathrm{~L} / \mathrm{mg}\right.$; $\mathrm{R}^{2}=0.85$ ). In addition, from literature it is also found that the adsorption capacity of anions by ion exchange resin follow the following order for removing anions: $\mathrm{Cl}^{-}<\mathrm{NO}_{3}<\mathrm{SO}_{4}^{2-}<\mathrm{HCO}_{3}^{-}<\mathrm{PO}_{4}^{3-}$ for _ granulated ferric hydroxide sorbent and $\mathrm{Cl}^{-} \mathrm{rv}$ $\mathrm{NO}_{3}<\mathrm{SO}_{4} \quad \mathrm{rv} \mathrm{HCO}_{3}<\mathrm{PO}_{4}$ for activated aluminium oxide sorbent (Loganathan et al., 2014). An ion exchange resin or adsorbent concentration of $1-3 \mathrm{~g} / \mathrm{L}$ of the volume of the reactor was employed in this work. The removal of P could be increased to $99-100 \%$ by increasing the dose of ion exchange resins/adsorbent. The transmembrane pressure (TMP) development was very low at $0.01 \mathrm{kPa} / \mathrm{h}$ throughout the experimental period. Thus, it can be 


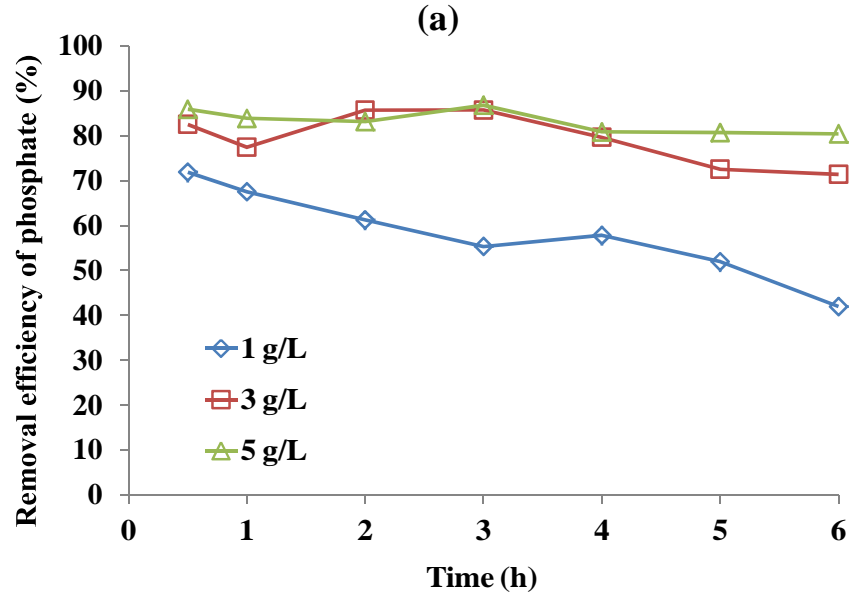

(b)

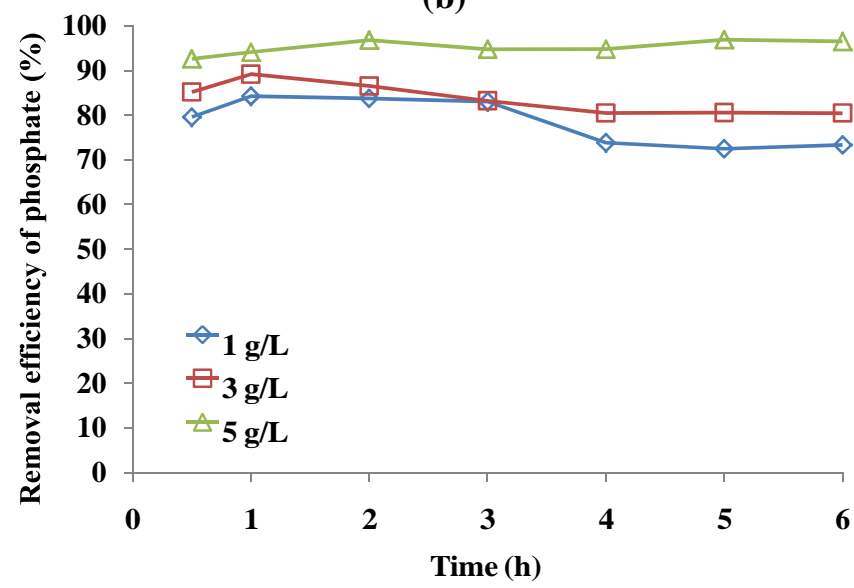

Fig. 1. Removal efficiency of phosphate by membrane adsorption hybrid system from HR-MBR effluent (a) Dowex' $21 \mathrm{~K}$ XLT and (b) zirconium (IV) hydroxide.

concluded that, membrane adsorption hybrid system could be an effective treatment system for the removal of phosphate from HR-MBR effluent. This results in lower discharge of $\mathrm{P}$ which will minimise the adverse effect on the receiving water body.

\subsection{Regeneration and cost estimation}

Ion-exchange/adsorption processes using selective ionexchange resins/adsorbent are suitable for the removing of phosphate to near-zero levels. However, after a long period of usage they become saturated and their removal efficiency declines. No experiments were conducted on the regeneration of the resins/ adsorbent used for the removal of phosphorus from wastewater. However, from the literature, it is evident that when the ion exchange resins/adsorbent are exhausted, the sorbents can be regenerated using a different regeneration reagent or a mixture of reagent (e.g. $\mathrm{NaCl}, \mathrm{NaOH}, \mathrm{CaCl}_{2}, \mathrm{HCl}, \mathrm{Na}_{2} \mathrm{CO}_{3}$, etc.) (Loganathan et al., 2014). For example, Chitrakar et al. (2006) used 0.1 M NaOH solution for the regeneration of $\mathrm{Zr}$ hydroxide (amorphous). After first regeneration, the adsorption of phosphate decreased slightly but remained constant for five cycles. In another study, Nur et al. (2014) used 1.0 M NaOH solution for the regeneration of iron oxide impregnated strong base anion exchange resin and found that the removal efficiency of phosphate was reduced slightly (10\%) even after the third cycle. Furthermore, $\mathrm{NaCl} /$ carbonate solution can be used for the regeneration of Dowex (strong base anion exchange resin) as recommended by the supplier. Thus, the ion exchange
resins/Zr hydroxide can be reused several times until the adsorption capacity is significantly decreased. Further, the exhausted $\mathrm{Zr}$ hydroxide can be used with cement or to produce ceramics which is a safe method of disposal.

The material cost for removing $1 \mathrm{mg}$ of $\mathrm{P}$ using $\mathrm{Zr}$ hydroxide and Dowex ranges from U\$ 0.004-0.011. The previous study showed that the unit cost (only material) for the removing of $1 \mathrm{mg}$ of $\mathrm{P}$ using titanium mesostructure, zirconium mesostructure, layered double hydroxides, alumina, and ion exchange resins ranges from \$0.033-1.15 (Choi et al., 2011). This indicates the ion exchange resins/adsorbent used in this study was comparatively cheaper than other ion exchange resins. The membrane plant treatment cost is US\$ $0.3-0.5$ per $\mathrm{m}^{3}$ (Adham et al., 1996; Gnirss and Dittrich, 2000).

\section{Conclusions}

The MBR operated at flux of $30 \mathrm{~L} / \mathrm{m}^{2} \mathrm{~h}$ could highly remove organic carbon but its phosphorus removal was low. A posttreatment of membrane adsorption hybrid system was therefore necessary to remove further phosphate from HR-MBR effluent. This will ensure reliable removal of nutrients and also pave a way for recovery of nutrients Overall, this hybrid process is helpful in the concurrent removal of organic and phosphorus from wastewater.

\section{Acknowledgement}

This work was funded by an Australian Research Council Discovery Research Grant (DP1092603).

\section{References}

Adham, S.S., Jacangelo, J.G., Laine, J.M., 1996. Characteristics and costs of MF and UF plants. J. AWWA 88, 22-31.

APHA, AWWA, WEF, 1998. Standard Methods for the examination of Water and Wastewater, 20th ed. American Public Health Association, Washington, DC.

Chen, J.P., Chua, M.L., Zhang, B., 2002. Effects of competitive ions, humic acid, and $\mathrm{pH}$ on removal of ammonium and phosphorous from the synthetic industrial effluent by ion exchange resins. Waste Manage. 22, 711-719.

Chitrakar, R., Tezuka, S., Sonoda, A., Sakane, K., Ooi, K., Hirotsu, T., 2006. Selective adsorption of phosphate from seawater and wastewater by amorphous zirconium hydroxide. J. Colloid Interface Sci. 297, 426-433.

Choi, J.W., Lee, S.Y., Park, K.Y., Lee, K.B., Kim, D.J., Lee, S.H., 2011. Investigation of phosphorous removal from wastewater through ion exchange of mesostructure based on inorganic material. Desalination 266, 281-285.

EUROMBRA, (2005). Membrane bioreactor technology (MBR) with an EU perspective for advanced municipal wastewater treatment strategies for the 21st century, Contract No. 018480, Deliverable Report - D5, INSA Toulouse, France.

Gnirss, R., Dittrich, J., 2000. Microfiltration of municipal wastewater for disinfection and advanced phosphorus removal: results from trials with different smallscale pilot plants. Water Environ. Res. 72, 602-609.

Johir, M.A.H., George, J., Vigneswara, S., Kandasamy, J., Grasmick, A., 2011a. Removal and recovery of nutrients by ion exchange from high rate membrane bio-reactor (MBR) effluent. Desalination 275, 197-202.

Johir, M.A.H., Aryal, R., Vigneswaran, S., Kandasamy, J., Grasmick, A., 2011b, Influence of supporting media in suspension on membrane fouling reduction in submerged membrane bioreactor (SMBR). J. Membr. Sci. 374, 121-128.

Johir, M.A.H., George, J., Vigneswaran, S., Kandasamy, J., Sathasivan, A., Grasmick, A., 2012. Effect of imposed flux on fouling behavior in high rate membrane bioreactor. Bioresour. Technol. 122, 42-49.

Liu, H., Sun, X., Yin, C., Hu, C., 2008. Removal of phosphate by mesoporous $\mathrm{ZrO}_{2}$. J. Hazard. Mater. 151, 616-622.

Loganathan, P., Vigneswaran, S., Kandasamy, J., Bolan, N.S., 2014. Removal and recovery of phosphate from water using sorption. Crit. Rev. Environ. Sci. Technol. 44, 847-907.

Long, F., Gong, J.L., Zeng, G.M., Chen, L., Wang, X.Y., Deng, J.H., Zhang, X.R., 2011. Removal of phosphate from aqueous solution by magnetic Fe- $\mathrm{Zr}$ binary oxide. Chem. Eng. J. 171, 448-455.

Monclús, H., Sipma, J., Ferrero, G., Rodriguez-Roda, I., Comas, J., 2010. Biological nutrient removal in an MBR treating municipal wastewater with special focus on biological phosphorus removal. Bioresour. Technol. 101, 3984-3991.

Nguyen, T.T., Ngo, H.H., Guo, W.S., Li, J.X., Listowski, A., 2012. Effects of sludge concentrations and different sponge configurations on the performance of a sponge-submerged membrane bioreactor. Appl. Biochem. Biotechnol. 167, 1678-1687. 
Nur, T., Johir, M.A.H., Loganathan, P., Nguyen, T., Vigneswaran, S., Kandasamy, J., 2014. Phosphate removal from water using an iron oxide impregnated strong base anion exchange resin. J. Ind. Eng. Chem. 20, 1301-1307.

Radjenović, J., Matošić, M., Mijatović, I., Petrović, M., Barceló, D., 2008. Membrane bioreactor (MBR) as an advanced wastewater treatment technology. Hdb. Environ. Chem. 5, 37-101.

Samatya, S., Kabay, N., Yuksel, U., Arda, M., Yuksel, M., 2006. Removal of nitrate from aqueous solution by nitrate selective ion-exchange resins. React. Funct. Polym. 66, 1206-1214.
Shanmuganathan, S., Johir, M.A., Nguyen, T.V., Kandasamy, J., Vigneswaran, S., 2015. Experimental evaluation of microfiltration-granular activated carbon (MFGAC)/nano filter hybrid system in high quality water reuse. J. Membr. Sci. 476, $1-9$.

Sun, F.Y., Wang, X.M., Li, X.Y., 2013. An innovative membrane bioreactor (MBR) system for simultaneous nitrogen and phosphorus removal. Process Biochem. 48, 1749-1756. 